\title{
Food intake and Physical activity of Hemodialysis Patient Undergoing Treatment at National Kidney Center, Kathmandu, Nepal
} Bhupal Baniya1, Hari Shankar Joshi², Sanjeev Regmi ${ }^{3}$, Kshitiz Upadhyay-Dhungel ${ }^{4}$

\author{
College of Applied Food and Dairy Technology (CAFODAT) \\ Kathmandu, Nepal
}

${ }^{1}$ Dietetian, Nepal Police Hospital Maharajgunj

${ }^{2}$ Lecturer, Department of Food chemistry and Engineering, CAFODAT

${ }^{3}$ Adjunctnt lecturer, Department of Microbiology, CAFODAT

${ }^{4}$ Professor, Department of Research and Planning, CAFODAT

\begin{abstract}
Background and Objectives: Nutrition has been an integral part of medical management in CKD patient in which total food and protein intake plays vital role in survival rate of patient. This study was done to investigate the nutritional status, food intake and physical activity level of hemodialysis patient for the period of three month in National Kidney center in Kathmandu.

Materials and Methods: Quantitative descriptive method was applied for the collection of data from 80 patients undergoing hemodialysis in National kidney center, Kathmandu. The data so obtained was further analyzed by using SPSS 16 version software and Microsoft excel sheet.

Discussion: The BMI result of sample population underdoing hemodialysis showed that $12 \%$ of them were underweight, $9 \%$ were overweight, $57 \%$ were in normal range and 1\% were obese. Similarly $42.5 \%$ of sample population were involved in some kind of physical activity where as $57.5 \%$ of the patient were not involved in any sort of physical activity. On the other hand, $52.5 \%$ of MHD patient did not follow the instruction provided in food chart and only $47.5 \%$ patient consume food according to diet chart.

Conclusion: The patient should be provided nutritional counseling before starting dialysis so that nutritional challenges could be reduced. As poor nutritional intake, Socio economic barrier, low physical activity level etc. are major problem of dialysis patient.
\end{abstract}

Key Words: Patient, Chronic Kidney Diseases, Hemodialysis, Nutritional status, Food intake, Phvsical activity

INRODUCTION

Chronic kidney diseases (CKD) are common progressive health problem affecting world population and contributing to significant morbidity and mortality of human beings. Chronic kidney diseases includes condition That damage kidney and decreases their ability to excrete waste products from blood and urine. According to different data available, the chronic kidney diseases are mainly caused by diabetes, high blood pressure and other different clinical renal disorders. Now day's chronic kidney diseases is global health problem and its prevalence is increasing dramatically. Among the many problems chronic kidney diseases (CKD) 
accounts one of the major challenge of Nepal. Different data available in different hospital record showed that $\mathrm{CKD}$ is increasing in alarming rate in Nepal.

In the past half century, the wide spread use of hemodialysis (HD) to prolong life of End Stage Renal diseases (ESRD) patient has been a remarkable achievement in preventing death from Uremia. Nowadays this therapy has expanded widely and is being used by elderly patient population leading to significant economic consequences to patient and health care system.

In the past few year medical field has developed significant technological and pharmacological improvements. Although some evidence suggests that mortality rate among the dialysis patient has decreased over the last few years but patient's survival is still low.

In End - Stage Renal Diseases patient often suffer from poor appetite, Various Comorbidities and various dietary restrictions. In addition to regular hemodialysis, nutritional balance is also very important. Researches suggest that low quality life style, Infection, Metabolic acidosis and oxidative stress may cause further complications which ultimately increases mortality rate [1].

Malnutrition is highly prevalent and strongly associated with mortality risk in the hemodialysis patient. In these patient malnutrition causing factors are low food intake and food intake characteristics. Thus early identification patient with eating behavior disturbances could potentially reduce the burden of malnutrition through appropriate nutritional interventions.

\section{MATERIALS AND METHODS}

This study was conducted in National Kidney Center, Kathmandu. Quantitative Research method given by WFP, 2012 with little modification was used during data collection. Data was collected through direct interview after reviewing medical records of each patient and recirculation test carried out in same dialysis session. The interview questionnaires were generated by reviewing the various articles on chronic kidney diseases. Socio-demographic details, life style, food habits, physical activity, nutritional status, knowledge on renal nutrition and dietary behavior were the questioned during interview. Depending upon the research questions, participants were assigned to collect data on participant and situational characteristics in order to statistically control for their influence on depend or outcome variable. Thus, obtained data was further processed and analyzed by using SPSS 16 version.

\section{RESULTS}

The sociodemographic profiles of the participants are presented in table 1 . Various Comorbid factors of the HD patients are presented in table 2. Hypertension is the most common comorbid factor followed by diabetes. Table 3 and 4 describes nutrition status of HD patients in terms of total energy intake, protein intake and albumin profile. Physical activity details of the participants are presented in table 5. Diet counselling profile of patients is presented in table 6 . About $94 \%$ of patient followed nutrition chart and about 84\% received diet counselling from the dietitian which is extremely good result in context of Nepal. 
Janaki Medical College Journal of Medical Sciences (2016) Vol. 4 (1): 33-40

\begin{tabular}{|c|c|c|c|}
\hline \multicolumn{4}{|c|}{ Patients Socio-demographic profile } \\
\hline Variables & Categories & Frequency (n) & Percent (\%) \\
\hline \multirow[t]{7}{*}{ Age groups } & $20-30$ & 8 & 10 \\
\hline & $30-40$ & 29 & 36.2 \\
\hline & $40-50$ & 15 & 18.8 \\
\hline & $50-60$ & 9 & 11.2 \\
\hline & $60-70$ & 9 & 11.2 \\
\hline & $70-80$ & 10 & 12.5 \\
\hline & Total & 80 & 100.0 \\
\hline \multicolumn{4}{|c|}{ Marital status of Patient } \\
\hline \multirow[t]{6}{*}{ Marital status } & Married & 67 & 83.8 \\
\hline & Single & 8 & 10.0 \\
\hline & Divorced & 1 & 1.2 \\
\hline & Widowed & 1 & 1.2 \\
\hline & Unmarried & 3 & 3.8 \\
\hline & Total & 80 & 100.0 \\
\hline \multicolumn{4}{|c|}{ Gender of patient } \\
\hline \multirow[t]{3}{*}{ Gender } & Male & 54 & 67.5 \\
\hline & Female & 26 & 32.5 \\
\hline & Total & 80 & 100.0 \\
\hline \multicolumn{4}{|l|}{ Income Source } \\
\hline \multirow[t]{7}{*}{ Income Source } & Employed & 5 & 6.2 \\
\hline & Unemployed & 22 & 27.5 \\
\hline & Pensioner & 12 & 15.0 \\
\hline & Housewife & 22 & 27.5 \\
\hline & Farmer & 14 & 17.5 \\
\hline & Businessman & 5 & 6.2 \\
\hline & Total & 80 & 100.0 \\
\hline
\end{tabular}

\begin{tabular}{|l|l|l|l|}
\hline \multicolumn{5}{|c|}{ Table 2: Comorbid Factors of HD patients } \\
\hline Diabetes & No & 61 & 76.2 \\
\hline & Yes & 19 & 23.8 \\
\hline & Total & $\mathbf{8 0}$ & $\mathbf{1 0 0}$ \\
\hline Hypertension & No & 5 & 6.2 \\
\hline & Yes & 75 & 93.8 \\
\hline & Total & $\mathbf{8 0}$ & $\mathbf{1 0 0}$ \\
\hline Renal disease & No & 77 & 96.2 \\
\hline & Yes & 3 & 3.8 \\
\hline & Total & $\mathbf{8 0}$ & $\mathbf{1 0 0}$ \\
\hline Renal calculi & No & 78 & 97.5 \\
\hline & Yes & 2 & 2.5 \\
\hline
\end{tabular}

Table 3: Nutritional status (Total energy and protein intake) Profile in HD patients $(\mathrm{N}=80)$

\begin{tabular}{|c|c|c|}
\hline Measures & Mean & SD \\
\hline Protein & 68.0505 & 33.7223 \\
& & \\
\hline Total energy & 1980.5250 & 43.27128 \\
& & \\
\hline
\end{tabular}




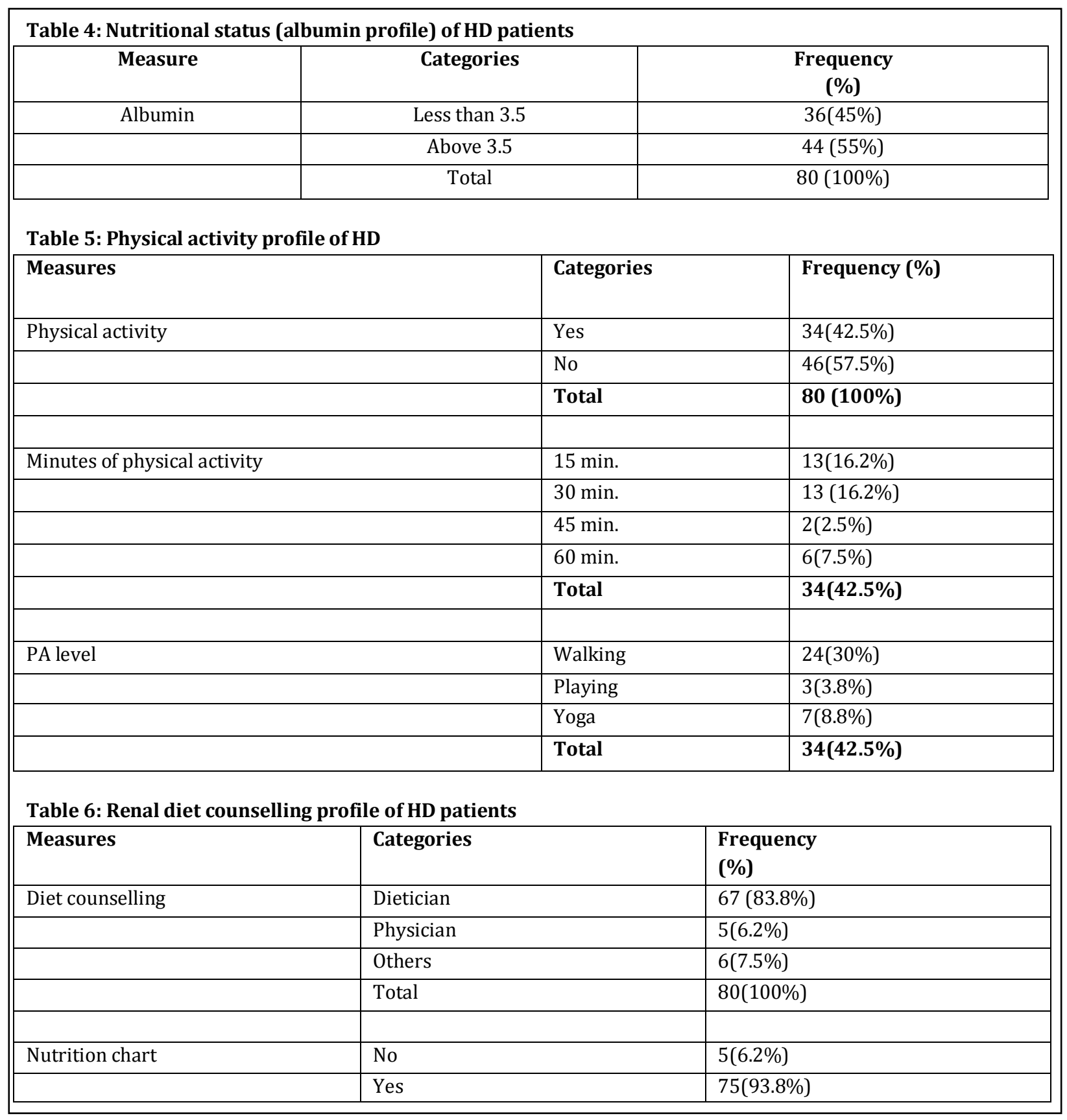

\section{DISCUSSION}

In this study patients of different age ranging from 20-80 years were enrolled. Among them the patient of the age group 30-40 has higher percent. Among all 80 patient doing hemodialysis $36.2 \%$ were of age group $30-40$ while only $10 \%$ patients of age group $20-30$ were recorded. Similarly, 83.3\% the percent married people were affected and were under hemodialysis while than the patient who were single, divorced, widowed and unmarried were least affected.

Among the total patients, the number of male patient was 54 which is $(67.5 \%)$ while female 
patient were only 26 (32.5\%). The income source of patient was also found to be associated with CKD. About $27.55 \%$ of total patient were found to be unemployed. Percentage of participation which was of the total while the patient who were employed and businessmen have least percent of participation. Among total participants, $23.8 \%$ were also suffering from diabetes, 93.8\% were also suffering from hypertensions, $2.5 \%$ had renal calculi and $3.5 \%$ had renal diseases.

Total energy intake: This study found that total dietary intake of respondent was varied from $3375 \mathrm{k} / \mathrm{Cal}$ to $679 \mathrm{k} / \mathrm{Cal}$ per day. According to this study, maximum number of patients did not fulfill the energy requirement per day. The mean value of energy supplied to HD patients was $1980.5 \mathrm{k}$ Cal per day. Stark et al (2011) also found that total energy consumption of HD patient was low.

Another research conducted also found that energy intake among HD patient was sub optimal [3]. A study conducted by Kopple (1994) found that HD patient with higher TG level had better chance of survival as compared to patient with low TG level.

A study conducted in 2013 showed association between diseases outcome and nutritional status of Kidney patient and concluded that average energy consumption and protein was below the recommended values [5]. Another study suggested that incidence of energy malnutrition is more severe than protein malnutrition in Kidney patients [6]. The research conducted in USA suggested that, appropriate nutrition management should be done to deficit the energy malnutrition [7].

Total dietary protein intake: The result of above study showed that, the highest protein intake of patient was $157 \mathrm{gm}$ and the lowest value of protein intake was $18 \mathrm{~g}$. The average protein intake was $68 \pm 33 \mathrm{gm}$. of protein per day. Study conducted by Almarken, 2004 showed that the mean dietary protein intake of HD patient was below the range of recommended. Various research conducted showed that low protein intake was associated with low serum albumin and causes mortality in HD population [9].

Another research conducted by Stark et al., 2011 [10]. Suggested that nutrition intake in adult, hemodialysis patient found that low protein intake in HD days as compare to other day and concluded that lower intake of protein on dialysis day might be due to disrupted meal schedule.

The retrospective analysis made by Shridhar and Joshyulla, 2013 [11], found that target serum level were not made by elderly and diabetes population undergoing $\mathrm{HD}$ and lower level of serum albumin was associated with low dietary protein intake.

Nutritional status of patients: The data obtained for nutritional status showed that $12 \%$ of the patient undergoing hemodialysis was underweight, $9 \%$ were overweight, $57 \%$ were in normal range and only $1 \%$ were obese. The mean value of BMI of patient was found to be $21.4 \pm 3.42$. Among the 80 patients $45 \%$ had less than $3.5 \mathrm{mg} / \mathrm{dl}$ of albumin level. Advancing age, Female gender and diabetes were significantly correlated with albumin level. The albumin level lesser than $3.8 \mathrm{mg} / \mathrm{dl}$ had impact on hospital stay, bacteremia, dialysis vintage, age and sex and also concluded that albumin level albumin level were not met in elderly, female and diabetic patient undergoing hemodialysis [11]. 
Anthropometric and biochemical sign of malnutrition are associated with increased mortality. Moreover, low serum albumin level is strong predictive factor that may reflect not only protein malnutrition but also influences several other morbidity factors such as dehydration, infection and other chronic diseases that initially increases death rate [1]. The dietary intervention and nutritional support seem to be effective in mitigating or correcting nutritional status [12]. The series of research conducted by different researcher showed the BMI and albumin level result similar to present research findings $[13,5]$.

The result obtained from current study was similar with different research conducted in different part of the world. However, in current study the albumin level data of all participant could not be collected which might be due to different economic burden faced by participant. Among the total population of HD patients about $45 \%$ of the patient could not continue their HD treatment their HD treatment due to economic problem [14]. Therefore, it can be concluded that people going HD in NKC cannot afford the cost of their treatments.

Knowledge on renal nutrition and dietary behavior: current study suggested among the total population about $67 \%$ received counselling from dietitian for renal diet whereas $6.2 \%$ received from physician. The result also showed that $47.5 \%$ of MHD patient consume food according to diet chart whereas $52.5 \%$ did not followed the instruction of diet chart.

According to a study, about $85.5 \%$ had diet prescription from dietitian and $58.5 \%$ did not followed diet chart instruction [15], which can be compared with current findings. Another research also demonstrated similar findings in which $17.7 \%$ never followed the instruction provided by diet char $t[8]$. The result of present study might be due to different social- economic barriers. Basaleem et al., 2004 found that about 58\% of HD population did not follow clear dietary instruction and evident poor intake of high quality protein, which is also similar to our findings. The result of current study might be due to different social economic barrier as per instruction provided by diet chart that suggested to consume high biological generating protein and prohibits different food items. The high biological protein is obtained from animal sources protein, which is costly for patient to consume daily in their diet.

Alteration on taste perception could be also another factor as people following diet chart were rule to follow same kind of food for period of time, which may trigger their frustration to avoid diet chart. The Nepalese people generally have their meal adding different condiments and spices and different religious barrier are present to consume food among ethnic group so diet instruction might also be barrier to different condiments and spices, which might raise the level of disagreement on diet chart instruction.

Physical Activity Level: The current study showed that only $42.5 \%$ of patients were involved in some kind of physical activity whereas majority of people i.e $57.5 \%$ of people were not involved in any kinds of exercise. Similar results was obtained in study conducted by Almarken, 2004 who showed that majority of patient i.e. approximately $95 \%$ of patient did not have physical activity and Chan, 2014 [3] also suggested that about $86 \%$ of the patient were physically inactive. HD patient had lower physical activity as compared to other patient 
due to different social aspects [5]. In present study of the total, people who were involved in some sort of physical activity most of the people preferred to walk from 15-30 min while less number of patient prefer playing.

\section{CONCLUSION}

The current study conclude that poor nutritional intake in terms of total calorie and protein, Socioeconomic barrier, lower adherence to nutritional advice and diet chart, low physical activity level were major problems of dialysis patient in National Kidney center. The patient should be provided nutritional counseling before starting dialysis so that nutritional challenges could be reduced.

Finally, the nutritional status of HD patient needs more attention and regular periodic nutrition assessment needs to be implemented every 3 months. Nepalese guidelines for various biochemical parameters and diet chart have to be designed for which there is need of Nutrition Dietetics.

\section{ACKNOWLEDGEMENT}

Authors are highly thankful to National Kidney Center, Kathmandu and CAFODAT, Kathmandu to carry out this research.

\section{AUTHOR'S CONTRIBUTION}

BB- Planning of research and script of first draft of manuscript; HSJ-collection of review literature and preparation of manuscript; SGverification of the prepared manuscript; KUD- supervision of research, critical review and final approval of manuscript.

\section{SOURCE OF SUPPORT: None}

CONFLICT OF INTEREST: Authors declared that there is no conflict of interest.

\section{REFERENCES}

1. Begstrom J. Nutrition and mortility in hemodialysis. J Am Soci Nephro 1995; 6: 13291341.

2. Stark S, Snetselaar L, Hall B, Stone RA, Pairano B, Mary AS. Nutritional intake in adult hemodialysis patients. Top Clin Nutria J 2011; 26(1): 45-46

3. Chain MC.Nutritional factors and clinical outcomes of patient with end stage kidney diseases implications for practice from researching the practice framework. Australia University of Wollongong 2014.

4. Kopple JD. Effect of nutrition on morbidity and mortality in maintenance dialysis patient. Am J Kidney Dise 1994; 6(24): 1002-1009.

5. Santos A, Machado M, Pereira L, Abreu J, Lyara M. Association between the level of quality of life and Nutritional status in patient undergoing chronic renal Hemodialysis. J Brazil Nephro 2013;35: 279-283.

6. Huidobro A, Velasco N, Rojas T. Prevalence of calorie protein malnutrition among patients in chronic hemodialysis. Rev Med Chil 2001; 129(5): 495-502.

7. Ikizler TA, Wingard RL, Sun M, Harvell J, Parker $\mathrm{R}$ and Hakim RM. Increase energy expenditure in Hemodialysis patients. Am J Cli nutri 1986; 43: 946-954.

8. Almakarem ZSA. Nutritional status assessment of the hemodialysis patient in Riyadh Al-Kharj Hospital, Saudi Arebia, King Saud University 2004.

9. Lukowsky LR, Kheifet SL, Arah OA, Nissenson AR, Zahed KK. IntJ Uro and Nephro 2014; 46: 129-140.

10. Stark S, Snetselaar L, Hall B, Stone R, Kim S, Piraino B, Sevick M. Nutritional intake in Adult hemodialysis patient. J Cli Nutri 2011; 26: 4656.

11. Sridhar NR, Joysulla S. Hypo albuminemia in hemodialysis end stage renal diseases patient, risk factors and relationship a two year single center study. BMC nephrology 2013; 14: 14712369.

12. Jadega JP, Kher V. Protein energy wasting in chronic kidney diseases. An update with focus 
in Nutritional management to improve outcomes. Ind J Endocrino and Meta 2012; 16.

13. Rao M, Sharma R, Juneja R, Jacob S, Jacob CK. Calculated nitrogen balance in hemodialysis patients influence protein intake. Kidney Int J 2000; 58: 336-345.

14. Chhetri PK, Mnandhar DN, Bhattrai SP, Pahari LR, Shrestha R. chronic kidney diseases 5 on hemodialysis in Nepal medical college teaching hospital. Nep Med J 2008; 10(1): 810.

15. Allharbi K, Enrione EB.Renal data from data Arab world. Saudi J kidney dise 2012; 23: 598608.

16. Basleem H, Alwan SM, Ahmed A, Sakkah AL. Assesment of Nutritional status of end stage renal diseases patient on maintenance hemodialysis, Saudi J Kidney dise 2004; 15: 455-462.

Correspondence to: Hari Shankar Joshi

Lecturer

Department of Food chemistry and Engineering, CAFODAT

Kathmandu, Nepal.

Email :- hyarishjoshi@gmail.com 